\title{
WTX inhibits gastric cancer migration through the reversal of epithelial-mesenchymal transition
}

\author{
DANLI YE ${ }^{1,2^{*}}$, WENXIA MA ${ }^{1,2^{*}}$, JIAHUI XU ${ }^{3}$, GUIFANG ZHU ${ }^{1,2}$, DEYING LIU ${ }^{4}$, \\ CHUN LIU ${ }^{5}$, YANQING DING ${ }^{1,2}$ and QINGLING ZHANG ${ }^{1,2}$ \\ ${ }^{1}$ Department of Pathology, Nanfang Hospital; ${ }^{2}$ Department of Pathology, College of Basic Medicine; \\ ${ }^{3}$ Guangdong Provincial Key Laboratory of Gastroenterology, Department of Gastroenterology, Nanfang Hospital; \\ Departments of ${ }^{4}$ Endocrinology and Metabolism and ${ }^{5}$ Pathology, Nanfang Hospital/First School of Clinical Medicine, \\ Southern Medical University, Guangzhou, Guangzhou 510515, P.R. China
}

Received April 24, 2017; Accepted December 7, 2017

DOI: $10.3892 / 01.2018 .9309$

\begin{abstract}
The aim of the present study was to investigate whether the expression of Wilms' tumor gene on $\mathrm{X}$ chromosome (WTX) affected the epithelial-mesenchymal transition (EMT) process and migration of gastric cancer cells. Stable WTX-overexpressing AGS cells (AGS.W) were established and analyzed by flow cytometry. The efficiency of the overexpression was verified by fluorescence microscopy, reverse transcription-quantitative polymerase chain reaction and western blotting. To analyze the expression of EMT-associated proteins, western blotting and immunofluorescence assays were performed. The migratory capability of the cells was detected by Transwell wound-healing assays, respectively. Compared with that of the control cells (AGS.veh), WTX expression was notably increased at mRNA $(\mathrm{P}<0.05)$ and protein levels $(\mathrm{P}<0.05)$ in the AGS.W gastric cancer cells. Morphological observations indicated that AGS.W cells transformed into spindle shapes, compared to AGS.veh cells, which maintained round or oval shapes. Furthermore, western blotting and immunofluorescence validated that the expression level of the epithelial marker epithelial-cadherin was significantly increased, whereas the expression levels of the mesenchymal markers neural-cadherin, $\beta$-catenin and vimentin were significantly decreased in the AGS.W cells compared with those in the AGS.veh cells. In addition, the overexpression of WTX decreased the migratory ability of AGS.W cells compared with AGS.veh cells. Exogenous expression of WTX inhibited
\end{abstract}

Correspondence to: Professor Qingling Zhang, Department of Pathology, College of Basic Medicine, Southern Medical University, 1838 North Guangzhou Da Dao, Guangzhou, Guangdong 510515, P.R. China

E-mail: zqllc8@126.com

${ }^{*}$ Contributed equally

Key words: Wilms' tumor on the $\mathrm{X}$ chromosome, epithelial-mesenchymal transition, migration, gastric cancer gastric cancer cell migration by reversing EMT. The results of the present study describe a molecular feature that may be a promising target for future gastric cancer therapy strategies.

\section{Introduction}

Gastric cancer (GC) ranks fourth in males and fifth in females for cancer incidence and $29 \%$ cancer deaths in 2012 worldwide (1). Although systematic therapeutic strategies such as trastuzumab, an anti-HER-2 monoclonal antibody, have already been used in clinical practice, the prognosis of patients with late-stage GC remains poor (2-4). Therefore, additional study into the molecular mechanisms underlying the morbidity and metastasis of GC remain important.

Epithelial-mesenchymal transition (EMT) is a complex molecular and cellular process involving the transformation of cells from an epithelial to a mesenchymal phenotype. Cells undergoing EMT are associated with increased cell mobility, invasiveness and reinforced resistance to apoptosis, all of which serve a crucial role in tumor progression $(5,6)$. Therefore, EMT has become an important topic of study with regard to the progression and metastasis of epithelial derived tumors (7). EMT is characterized by the downregulation of the epithelial marker epithelial (E)-cadherin, which promotes cell-cell contact, and the upregulation of mesenchymal markers, including vimentin and neural (N)-cadherin (6,8-10). Furthermore, the EMT process allows epithelial cells to switch from an immobile phenotype to a motile mesenchymal phenotype, leading to increased cell migration and invasion $(11,12)$. Liu et al (13) revealed that the expression of the mesenchymal markers $\mathrm{N}$-cadherin and vimentin in GC tissues were significantly increased compared with those in adjacent normal tissues, which indicated the involvement of EMT in GC oncogenesis. Zhang et al (12) also identified that $\mathrm{C}-\mathrm{C}$ motif chemokine receptor 7 promoted EMT in GC cells by regulating the expression of zinc finger protein SNAI1, resulting in migration and invasion of GC cells. Furthermore, previous studies have indicated that microRNA also serve as important regulators of GC EMT (14-17).

Wilms' tumor on the X chromosome (WTX) was the first tumor suppressor gene identified on the $\mathrm{X}$ chromosome, and has been a topic of study since its identification 
in 2007 (18). WTX has been demonstrated to serve a major role in tumor suppression in several somatic tumors, although data concerning its expression and function in GC are limited (19-22). Zhang et al (23) analyzed the expression of WTX in normal and cancer tissues, and identified that WTX gene and mRNA expression levels were decreased compared with those in normal tissue, which indicated that the WTX gene may serve an important role in tumor suppression of GC.

The present study aimed to investigate whether the WTX gene inhibited gastric cancer morbidity, and the role of EMT within this process. The results may provide novel insight for gastric cancer cell metastasis, and identify possible clinical targets for gastric cancer treatment.

\section{Materials and methods}

Cell lines and cell culture. The human gastric cancer AGS cell line and the $293 \mathrm{~T}$ cell line (only as transfection vectors) were obtained from the American Type Culture Collection (Manassas, VA, USA) and maintained in the Department of Pathology, Nanfang Hospital (Guangzhou, China). The human gastric cancer AGS cell line was cultured in RPMI-1640 medium supplemented with $10 \%$ fetal bovine serum (FBS; both Gibco; Thermo Fisher Scientific, Inc., Waltham, MA, USA) at $37^{\circ} \mathrm{C}$ in a humidified atmosphere of $5 \% \mathrm{CO}_{2}$. The 293T cells were cultured in DMEM (Gibco; Thermo Fisher Scientific, Inc.) medium supplemented with $10 \% \mathrm{FBS}$ at $37^{\circ} \mathrm{C}$ in a humidified atmosphere of $5 \% \mathrm{CO}_{2}$.

Establishment of stable WTX-overexpressing and control gastric cancer cell lines. The detailed methods of the establishment of stable WTX-overexpressing colorectal cancer SW620 cell line were described previously (24). The whole length of WTX CDS region is 3405 bp in length (based on NCBI information on APC membrane recruitment protein 1; NM_152424.3; https://www.ncbi.nlm.nih.gov/gene/139285). The region was amplified from a WTX CDS clone vector (Shanghai GeneChem Co., Ltd., Shanghai, China), using a pair of primers as follows: Forward, 5'-ACCGGTCGCCACCATGGAGACCCAAAA GGATGAAGCTGCTC-3 and reverse, 5'-ACCCTTGGCTAG GTTTCCATTCATGGCAGTG-3. The polymerase chain reaction (PCR) kit was provided by Takara Biotechnology, Co., Ltd. (Dalian, China). Thermocycling conditions were as follows: $94^{\circ} \mathrm{C}$ for $5 \mathrm{~min}$, followed by 30 cycles of $94^{\circ} \mathrm{C}$ for $30 \mathrm{sec}, 55^{\circ} \mathrm{C}$ for $30 \mathrm{sec}$ and $72^{\circ} \mathrm{C}$ for $2 \mathrm{~min}$, followed by $72^{\circ} \mathrm{C}$ for $10 \mathrm{~min}$.

Subsequent to the PCR amplifying process, the PCR product was subcloned into the GV287 lentivirus vector using BamHI/AgeI restrictive enzymes. Agarose gel electrophoresis was then used to evaluate the recombinant vector, followed by Sanger sequencing to confirm the recombinant vector was successfully constructed.

Subsequently,293T cells were transfected(Lipofectamine ${ }^{\mathrm{TM}}$ 2000 Transfection Reagent; Thermo Fisher Scientific, Waltham, MA, USA) with packaging vectors and the WTX recombinant lentivirus plasmid or control vector. The supernatant containing Lenti-virus was collected and concentrated by Shanghai GeneChem Co., Ltd. and the titer was measured.

AGS cells were seeded in a 24 -well plate at a density of $30-50 \%$ at $37^{\circ} \mathrm{C}$ for $24 \mathrm{~h}$ prior to being infected with WTX CDS overexpression lentiviruses or control lenti-virus based on the virus titer and multiplicity of infection (MOI) value of the AGS cell line (MOI=50). Transfection efficiency was roughly evaluated by fluorescence microscopy at magnification, x100 $48 \mathrm{~h}$ following infection and was finally verified by reverse transcription-quantitative PCR (RT-qPCR) and western blotting. The pure WTX overexpression cells and control cells were isolated by flow cytometry and named as AGS.W and AGS.veh cells.

$R T$ - $q P C R$. AGS.W and AGS.veh cells were seeded in 6-well plates at a density of $1 \times 10^{6}$ cells/well in advance for $24 \mathrm{~h}$ and cells were washed 3 times with PBS. The cells were collected, and cellular mRNA was extracted with RNAiso-Plus (Takara Bio, Dalian, China), from which single-stranded cDNA was then synthesized at $37^{\circ} \mathrm{C}$ for $15 \mathrm{~min}, 85^{\circ} \mathrm{C}$ for $5 \mathrm{sec}$ and stored at $4^{\circ} \mathrm{C}$. Using the qPCR cDNA synthesis kit (Takara Bio, Dalian, China) following the manufacturer's protocol. qPCR was conducted with $\mathrm{iQ}^{\mathrm{TM}}$ SYBR-Green Supermix (Takara Bio, Dalian, China) using Applied Biosystems 7500 Sequence Detection system. The thermo cycling condition were as follows: $95^{\circ} \mathrm{C}$ at $5 \mathrm{~min}$ for $1 \mathrm{cycle}$, then $95^{\circ} \mathrm{C}$ for $5 \mathrm{sec}, 60^{\circ} \mathrm{C}$ for $30 \mathrm{sec}$ and $72^{\circ} \mathrm{C}$ for $34 \mathrm{sec}$ for 40 cycles, followed by the melting curve stage $\left(95^{\circ} \mathrm{C}\right.$ for $15 \mathrm{sec}, 60^{\circ} \mathrm{C}$ for $1 \mathrm{~min}$ and $95^{\circ} \mathrm{C}$ for $\left.30 \mathrm{sec}\right)$. The relative WTX mRNA level was calculated as $2^{-\Delta \Delta \mathrm{Cq}}(25)$. The sense and anti-sense WTX and GAPDH primers used are listed below: WTX forward, 5'-GACCCAAAAGGATGA AGCT-3' and reverse, 5'-CCCCTCCAAAGAAACTAGGC-3'; GAPDH forward, 5'-TGAAGGTCGGAGTCAACGGA-3' and reverse, 5'-CCATTGATGACAAGCTTCCCG-3'.

Western blot analysis. AGS.W and AGS.veh cells were washed 3 times with PBS prior to being lysed with Radioimmunoprecipitation Assay Lysis buffer (KeyGen Biotech Co., Ltd., China). Cellular protein lysate was separated from the residue through high-speed centrifugation $\left(12,000 \mathrm{x} \mathrm{g} ; 30 \mathrm{~min} ; 4^{\circ} \mathrm{C}\right)$ and mixed with loading buffer (Beyotime Institute of Biotechnology, Haimen, China). The mixture was then boiled for 5 min for protein denaturation. The total protein was determined using a bicinchoninic acid assay. Samples (40 $\mu \mathrm{g} /$ lane) were subjected to SDS-PAGE (10\% gel), transferred to $0.45 \mu \mathrm{m}$ polyvinylidene fluoride membrane (EMD Millipore, Billerica, MA, USA), blocked with $5 \%$ non-fat milk (diluted in PBS with $0.1 \%$ Tween at $25^{\circ} \mathrm{C}$ for $1 \mathrm{~h}$ ) and incubated with primary antibodies overnight at $4^{\circ} \mathrm{C}$ and secondary antibodies at $25^{\circ} \mathrm{C}$ for $1 \mathrm{~h}$. An enhanced chemiluminescence detection system (Fu De Biological Technology Co., Ltd, Hangzhou, China) was used to visualize protein expression. Anti- $\beta$-actin antibody was used as a loading control. Protein bands were examined using the ChemiDoc ${ }^{\mathrm{TM}}$ Imaging system (version. 5.2.1). Data were quantified using Image Lab (version. 5.2.1; both Bio-Rad Laboratories, Inc.).

Primary antibodies included rabbit monoclonal antibodies anti-WTX (cat. no. ab91309; 1:500), anti-N-cadherin (cat. no. ab76057; 1:500), anti- $\beta$-catenin (cat. no. ab27798; 1:500) anti-Vimentin (cat. no. ab27608; 1:500), anti-E-cadherin (cat. no. ab76319; 1:500; all Abcam, Cambridge, UK) and mouse monoclonal antibody anti- $\beta$-actin (cat. no. TA-09; 1:500; OriGene Technologies, Inc., Beijing, China).

Secondary antibodies included horseradish peroxidase-conjugated goat anti-rabbit Immunoglobulin G 

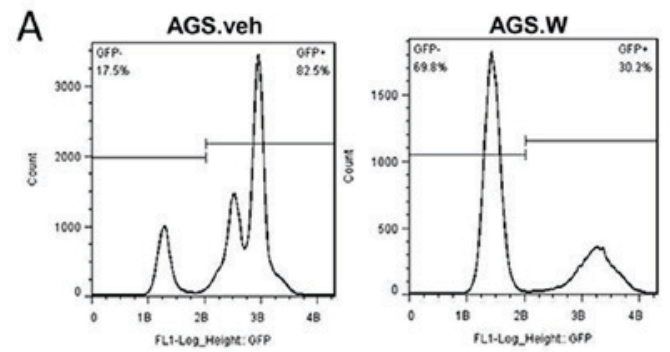

B
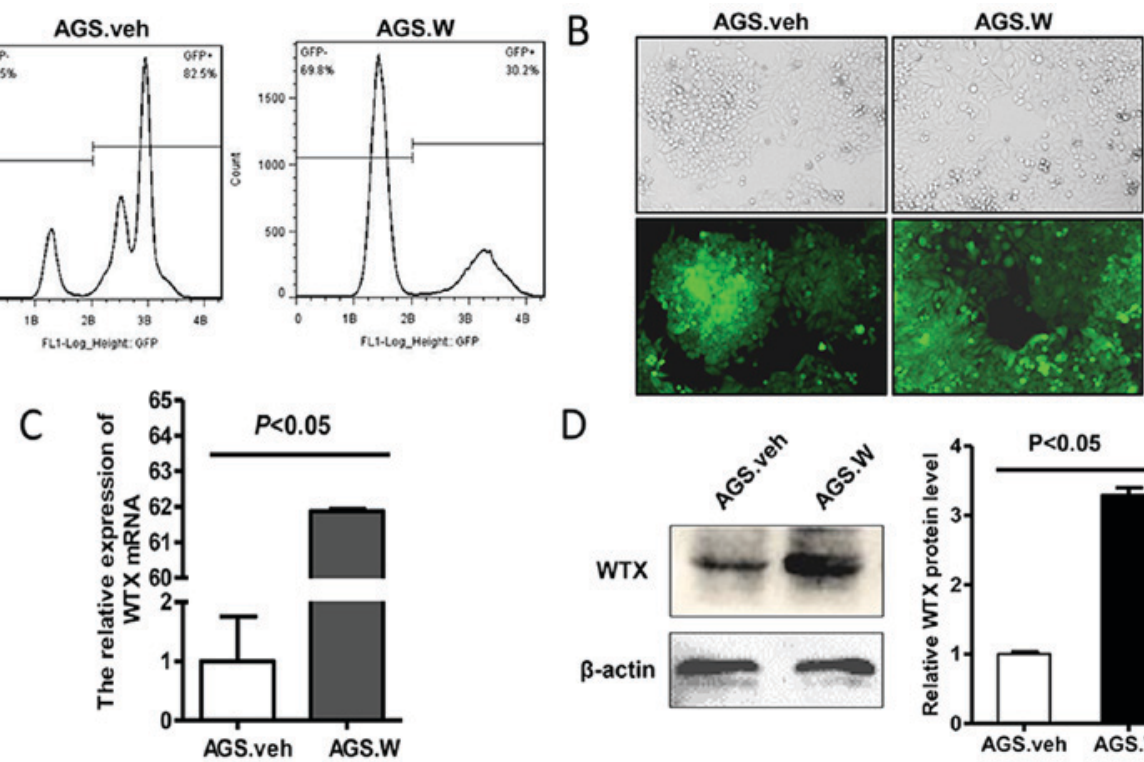

D

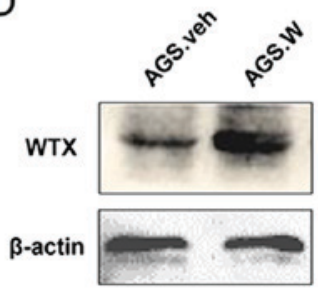

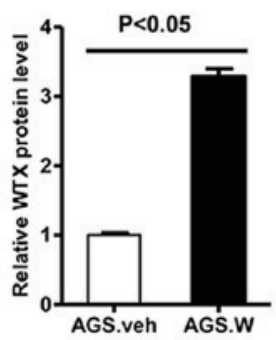

Figure 1. Establishment of stable WTX-overexpressing AGS cell line. (A) Flow cytometry and (B) fluorescence microscopy were used to evaluate the infection efficiency. Magnification, x100. (C) Reverse transcription-quantitative polymerase chain reaction assay was used to measure the WTX mRNA level of AGS.W and AGS.veh cells ( $\mathrm{n}=4$; P<0.05), the normalization gene was GAPDH. (D) Western blotting was performed to analyze WTX protein expression in AGS.W and AGS.veh cells. The bar graph depicts the relative expression of protein normalized to $\beta$-actin. WTX, Wilms' tumor on the X chromosome; AGS.W, AGS cell line stably overexpressing WTX; AGS.veh, negative control.

(cat. no. ZB-2301; 1:1,000) and peroxidase-conjugated goat anti-mouse Immunoglobulin G (cat. no. ZB-2305; 1:1,000; both OriGene Technologies, Inc.).

Cell morphology observation. AGS.W and AGS.veh cells were seeded in 6-well plate (Corning Inc., Coring, NY USA) and grown to a density of $70-80 \%$, prior to being subjected to morphology observation with an Olympus IX71 inverted light microscope (Olympus Corporation, Tokyo, Japan) at magnification, $\mathrm{x} 200$ in 5 random fields.

Immunofluorescence to detect changes in EMT-associated proteins expression. AGS.W and AGS.veh cells were first seeded at a density of $10 \%$ (300 cells/well) on confocal disks and then cultured with full medium for $12 \mathrm{~h}$. Cells were washed with PBS 3 times, and then fixed in $4 \%$ formaldehyde for $30 \mathrm{~min}$ at room temperature, followed by permeabilization with $0.2 \%$ Triton-100 for $15 \mathrm{~min}$ at room temperature and incubation with specific primary antibodies against the EMT-associated proteins [anti-N-cadherin (cat. no. ab76057; 1:200), anti- $\beta$-catenin (cat. no. ab27798; 1:200), anti-Vimentin (cat. no. ab27608; 1:200), anti-E-cadherin (cat. no. ab76319; 1:200; all Abcam)] overnight at $4^{\circ} \mathrm{C}$. Cells were incubated with an Alexa Fluor-594 conjugated goat anti-rabbit Immunoglobulin G secondary antibody (cat. no. SA00006-4; 1:500; ProteinTech Group, Inc., Chicago, IL, USA) for $1 \mathrm{~h}$ at room temperature and finally stained with DAPI (Beyotime Institute of Biotechnology, Haimen, China) for $5 \mathrm{~min}$ at room temperature to prepare the samples for immunofluorescence analysis. All immunofluorescence images were captured using an Olympus confocal microscope (Fluoview FV1000; Olympus Corporation, Tokyo, Japan) at magnification, x1,200. The mean intensity of indicated proteins was quantified using Image J software (version 1.8.0; National Institutes of Health, Bethesda, MA, USA).
Transwell cell migration detection assay. Transwell migration assay was performed using Transwell inserts (BD Bioscience, SanJose, CA, USA) with a filter of $8 \mu \mathrm{m}$ pore. A total of $1 \times 10^{5}$ cells/chamber were seeded in the upper chamber with serum-free medium, and the concentration of FBS was increased to $20 \%$ in the lower chamber to serve as a chemoattractant. Cells were cultured for $48 \mathrm{~h}$, fixed with $4 \%$ paraformaldehyde for $30 \mathrm{~min}$ at room temperature, and then stained with hematoxylin for $30 \mathrm{~min}$ at room temperature. Cells invading to the opposite side of membrane were observed with an inverted light microscope at magnification, $\mathrm{x} 200$ and counted by direct visualization of nuclei in 5 different visual fields. A total of three independent experiments were conducted for statistical analysis.

Wound-healing assay. AGS.W and AGS.veh cells were seeded in a 6 -well plate at a density of $1 \times 10^{6}$ cells/well for $24 \mathrm{~h}$, and then scratched with a sharp $10-\mu l$ pipette tip. Floating cells were removed with PBS three times. Cell migration was observed with an Olympus IX71 inverted light microscope at x100 magnification in 5 random fields every $6 \mathrm{~h}$ for $72 \mathrm{~h}$, with images captured at each $6 \mathrm{~h}$ interval.

Statistical analysis. Statistical analysis was performed with SPSS 13.0 (SPSS, Inc., Chicago, IL, USA). A Student's independent t-test was used to compare the WTX mRNA levels and Transwell migration cell numbers between two groups. Data are presented as mean \pm standard deviation from three independent experiments. $\mathrm{P}<0.05$ was considered to indicate a statistically significant difference.

\section{Results}

Establishment of AGS.W by lentivirus infection combined with flow cytometry. Flow cytometry results are presented in Fig. 1A. AGS.W and control AGS.veh cells expressed green 
A
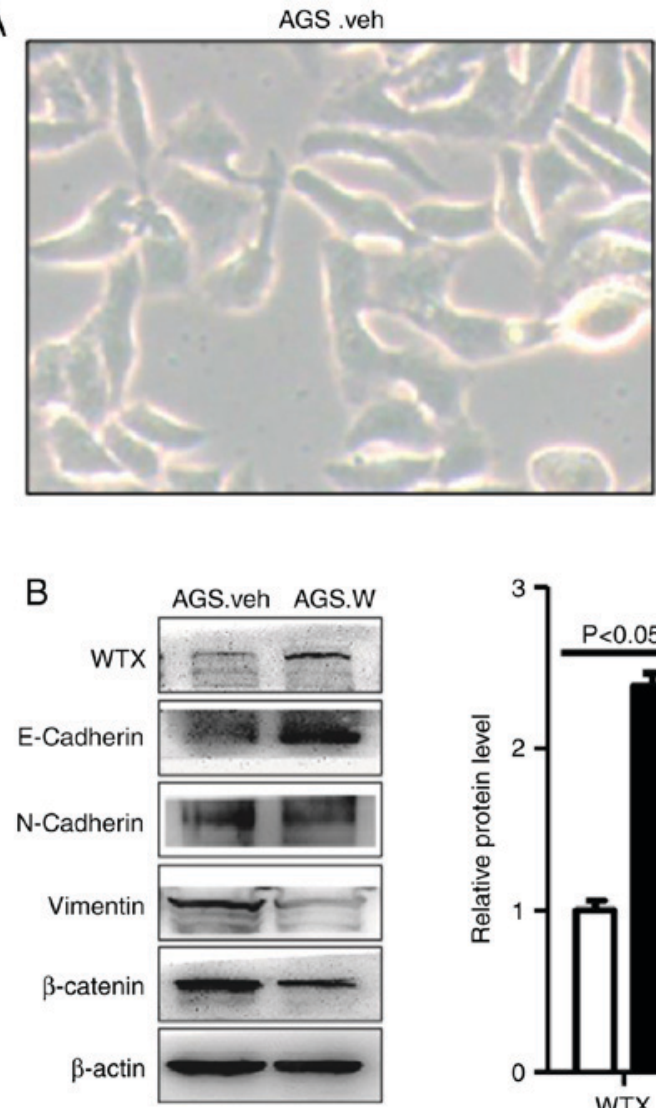

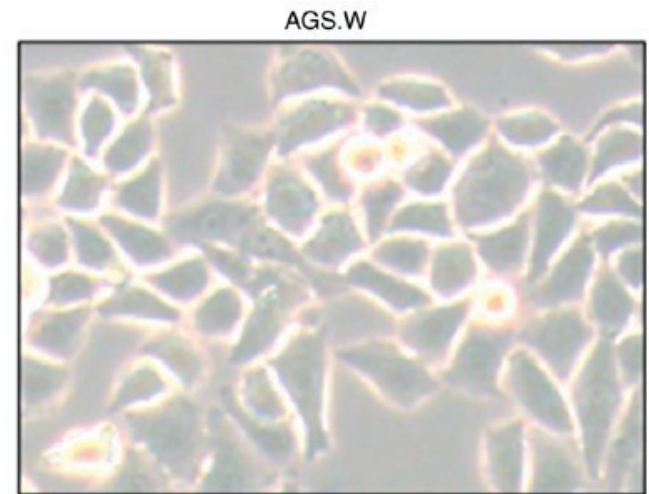

AGS.veh

AGS.W

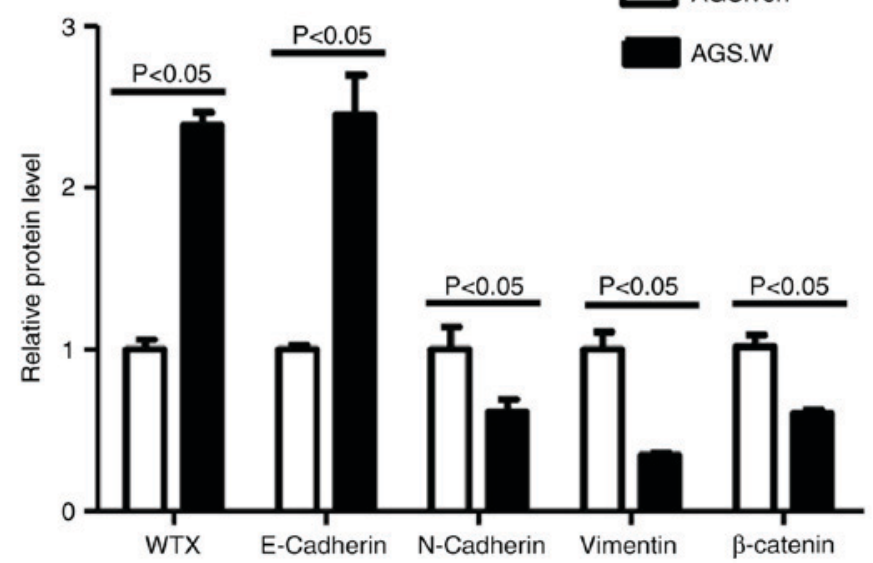

Figure 2. Morphology observation and EMT-associated protein expression levels in AGS.W and AGS.veh cells. (A) AGS.W and AGS.veh cells were subjected to morphological observation using light microscopy. Magnification, x200. (B) EMT-associated protein expression levels in AGS.W and AGS.veh cells were detected by western blotting. Bar graph depicts the relative expression of proteins normalized to $\beta$-actin. WTX, Wilms' tumor on the X chromosome; AGS.W, AGS cell line stably overexpressing WTX; AGS.veh, negative control; E-cadherin; epithelial cadherin; N-cadherin, neural cadherin; EMT, epithelial-mesenchymal transition.

fluorescence under the fluorescence microscope (Fig. 1B). Next, it was verified that AGS.W expressed significantly increased WTX at mRNA (Fig. 1C) and protein (Fig. 1D) levels, compared with AGS.veh cells, indicating that the recombinant AGS cell line with stable WTX overexpression was successfully established.

Morphological changes in AGS.W cells compared with AGS. veh cells. The morphology of AGS.W and AGS.veh cells was observed using microscopy, and it was identified that the (26), whereas AGS.veh cells retained a spindle shape and grew scattered (Fig. 2A). This morphological change is a phenotype of the tumor EMT process $(26,27)$.

\section{EMT-associated protein expression in AGS.W and AGS.veh} cells. To detect the levels of EMT-associated protein expression in AGS.W and AGS.veh cells, western blotting was performed. The results indicated that the level of epithelial marker E-cadherin was upregulated, while the levels of mesenchymal markers including $\mathrm{N}$-cadherin, vimentin and $\beta$-catenin were downregulated in AGS.W cells (Fig. 2B). Similar trends were observed in immunofluorescence (Fig. 3). These results validate the inhibitory effect of WTX on EMT in the AGS gastric cancer cell line.

Cell migration and invasion ability in AGS.W and AGS. veh cells. To determine whether WTX affects gastric cancer cell invasion and migration, a Transwell Matrige ${ }^{\circledR}$ invasion assay and an in vitro wound-healing assay were performed in AGS.W and AGS.veh cells. In the Matrigel ${ }^{\circledR}$ invasion assay, the number of AGS.W cells invading to the opposite side of chamber membrane was decreased compared with that of AGS. veh cells, indicating that the invasive capabilities of the AGS.W cells was decreased in comparison with those of the AGS.veh cells (Fig. 4A and B). The wound-healing assay also indicated that WTX overexpression markedly decreased the migration of AGS cells after $48 \mathrm{~h}$ (Fig. 4C). The present study demonstrated that WTX overexpression prohibited the invasive and migratory capabilities of the gastric cancer AGS cell line.

\section{Discussion}

An estimated 951,600 new stomach cancer cases and 723,100 mortalities occurred in 2012 (1). Most newly diagnosed cases are identified for cell migration and consequent metastasis (28). Due to early metastasis to distant organs, particularly the liver, the prognosis of patients with gastric cancer remains poor, despite the improving surgical resection technologies for early stage tumors (29-31).

WTX has been demonstrated to serve as a tumor suppressor in the oncogenesis of various tumors $(18,32)$. To investigate the exact mechanism of the WTX in GC, WTX-overexpressing cells were established, and it was identified that the overexpression of WTX may inhibit the invasive and migratory capabilities of 


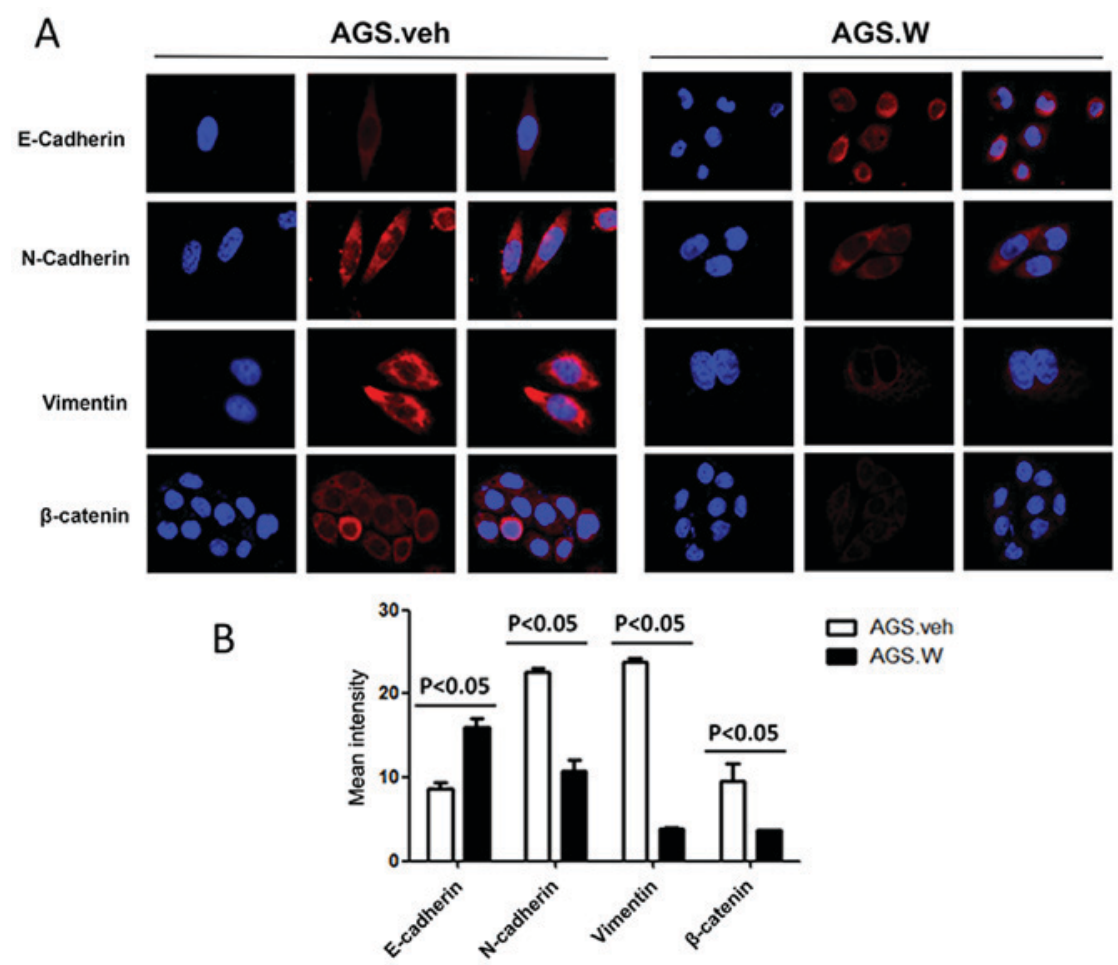

Figure 3. Immunofluorescent staining of epithelial-mesenchymal transition-associated markers in AGS.W and AGS.veh cells. (A) E-cadherin, $\beta$-catenin, $\mathrm{N}$-cadherin and vimentin were stained red; nuclei were stained blue. Magnification, x1,200. (B) Quantification of the intensity of indicated protein. E-cadherin; epithelial cadherin; N-cadherin, neural cadherin; WTX, Wilms' tumor on the X chromosome; AGS.W, AGS cell line stably overexpressing WTX; AGS.veh, negative control.

A

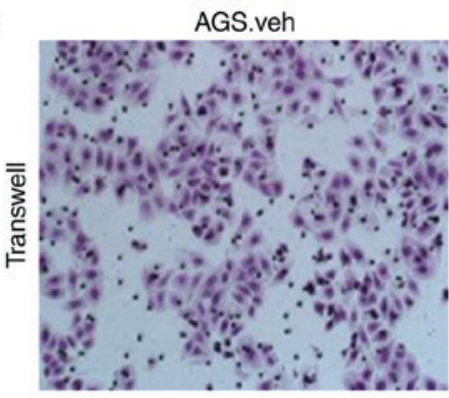

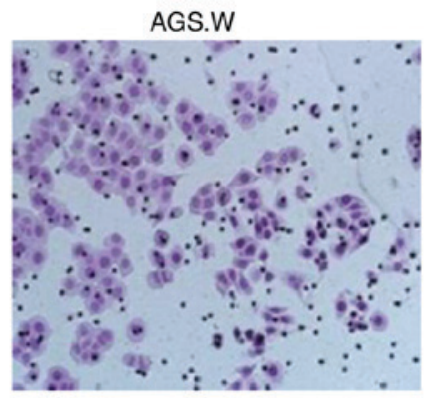

B

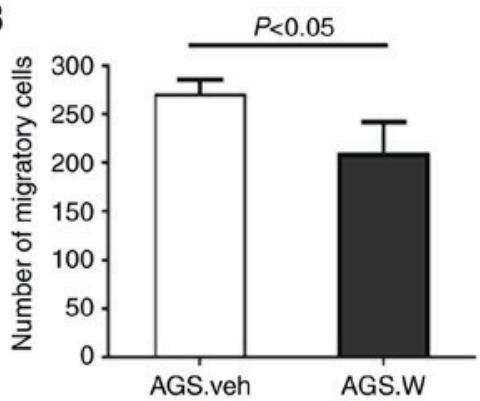

C

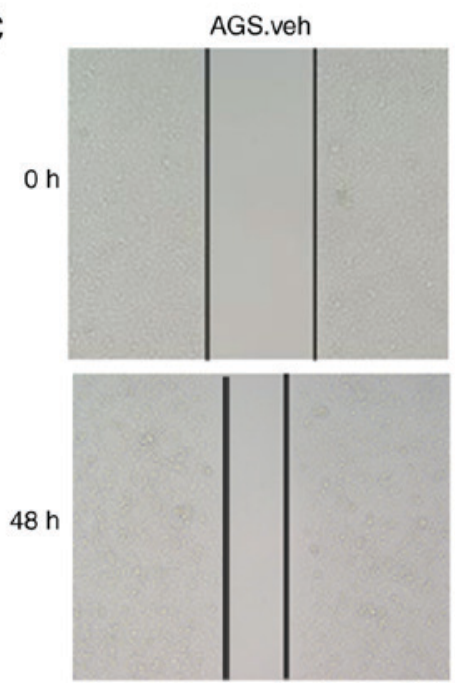

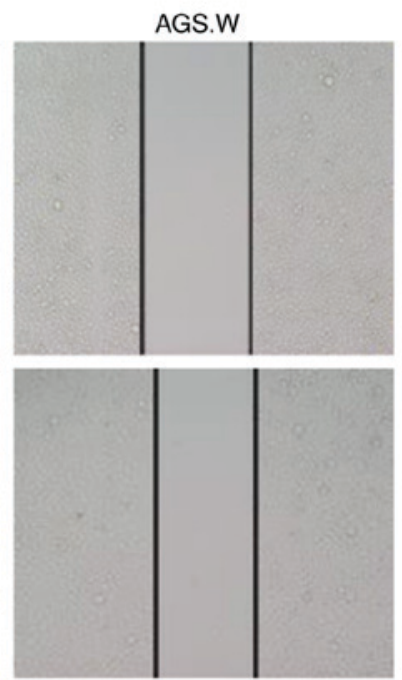

Figure 4. AGS.W and AGS.veh cell migration. (A) Cell migration was measured by Transwell Matrigel ${ }^{\circledR}$ assay (magnification, $\mathrm{x} 200$ ). (B) Transwell assay reported AGS.W (210.4 \pm 14.02$)$ acquired restraining cell migratory ability than AGS.veh cells (271.4 \pm 6.313$)$. Student's independent t-test was used to compare the data $(\mathrm{P}=0.0041)$. (C) Cell migration was measured by wound-healing assay (magnification, $\mathrm{x} 100)$. WTX, Wilms' tumor on the X chromosome; AGS.W, AGS cell line stably overexpressing WTX; AGS.veh, negative control. 
GC cells, indicating that the WTX gene may serve a pivotal role in tumor metastasis.

Previous studies have indicated that the EMT process is critical for the metastasis of GC by promoting cell migration and invasion (33). Notably, morphological changes were observed in the WTX-overexpressing cells, which transformed from a spindle, mesenchyme-like shape into an oval, epithelial shape. EMT is the physiological or pathological conversion of epithelial cells to mesenchymal cells, in which cells undergo phenotypic changes including the loss of cell polarity and cell-cell adhesion, and the acquisition of migratory and invasive properties, which are responsible for carcinoma progression. To confirm this hypothesis, the expression levels of EMT-associated proteins in WTX-overexpressing cells were analyzed, and it was identified that epithelial cell adhesion molecules including E-cadherin were upregulated, whereas mesenchymal markers, including $\mathrm{N}$-cadherin, vimentin and $\beta$-catenin, were downregulated by WTX overexpression. These results indicated that WTX may inhibit the EMT process, and consequently affect the migration of GC cells.

However, the mechanism by which WTX inhibited the EMT process and cell migration in gastric cancer cells was not elucidated. The Wnt/ $\beta$-catenin pathway has been demonstrated to serve an important role in the proliferation, differentiation, migration and adhesion of GC cells $(34,35)$. Heuberger and Birchmeier (36) revealed that E-cadherin binds to $\beta$-catenin and suppresses its nuclear localization by sequestering cytoplasmic $\beta$-catenin. Furthermore, Howard et al (37) revealed that the combination between $\beta$-catenin and E-cadherin is essential for the EMT process. Hlubek et al (38) demonstrated that $\beta$-catenin-dependent translation of target genes in the nuclei is key player during EMT. additionally, WTX has been demonstrated to negatively regulate the $\mathrm{Wnt} / \beta$-catenin signaling pathway by forming a complex with $\beta$-catenin, resulting in the promotion of complex degradation $(38,39)$. Therefore, we hypothesize that WTX may inhibit the EMT process in AGS gastric cancer cells through the suppression of the Wnt/ $\beta$-catenin pathway directly and/or indirectly associated with the upregulation of E-cadherin, which requires additional study for confirmation.

In conclusion, the present study identified that WTX may inhibit gastric cancer cell invasion and migration, and reverse the EMT process. The results indicate that WTX may be an important gene for future studies concerning the regulation of gastric cancer cell metastasis, and may present a novel prospective for understanding the molecular mechanisms that underlie this process. The present study provides insight on the potential for WTX-targeted therapy for patients with gastric cancer, with the aim of minimizing cancer progression and metastasis.

\section{Acknowledgements}

The authors thank Dr Guangning Yan (General Hospital of Guangzhou Military Command of PLA, Guangzhou, China) for reviewing the manuscript.

\section{Funding}

The present study was supported by the National Natural Science Foundation of China (grant nos. 81472712 and 81772918).

\section{Availability of data and materials}

The datasets used and/or analyzed during the current study are available from the corresponding author on reasonable request.

\section{Authors' contributions}

YD, QZ and DY designed the research. DY, JX, WM, CL, GZ and DL conducted the experiments, performed the data analysis and wrote the manuscript. DY and DL performed the assays. All authors discussed the results and reviewed the manuscript.

\section{Ethics approval and consent to participate}

Not applicable.

\section{Patient consent for publication}

Not applicable.

\section{Competing interests}

The authors declare that they have no competing interests.

\section{References}

1. Torre LA, Bray F, Siegel RL, Ferlay J,Lortet-Tieulent J and Jemal A: Global cancer statistics, 2012. CA Cancer J Clin 65: 87-108, 2015.

2. Li J, Zhen L, Zhang Y, Zhao L, Liu H, Cai D, Chen H, Yu J, Qi X and Li G: Circ-104916 is downregulated in gastric cancer and suppresses migration and invasion of gastric cancer cells. Onco Targets Ther 10: 3521-3529, 2017.

3. Zhang P, Tang WM, Zhang H, Li YQ, Peng Y, Wang J, Liu GN, Huang XT, Zhao JJ, Li G, et al: MiR-646 inhibited cell proliferation and EMT-induced metastasis by targeting FOXK1 in gastric cancer. Br J Cancer 117: 525-534, 2017.

4. Bang YJ, Van Cutsem E, Feyereislova A, Chung HC, Shen L, Sawaki A, Lordick F, Ohtsu A, Omuro Y, Satoh T, et al: Trastuzumab in combination with chemotherapy versus chemotherapy alone for treatment of HER2-positive advanced gastric or gastro-oesophageal junction cancer (ToGA): A phase 3, open-label, randomised controlled trial. Lancet 376: 687-697, 2010.

5. Legras A, Pecuchet N, Imbeaud S, Pallier K, Didelot A, Roussel H, Gibault L, Fabre E, Le Pimpec-Barthes F, Laurent-Puig P and Blons H: Epithelial-to-mesenchymal transition and MicroRNAs in lung cancer. Cancers (Basel) 9: pii: E101, 2017.

6. Kalluri R and Weinberg RA: The basics of epithelial-mesenchymal transition. J Clin Invest 119: 1420-1428, 2009.

7. He SJ, Xiang CQ, Zhang Y, Lu XT, Chen HW and Xiong LX: Recent progress on the effects of microRNAs and natural products on tumor epithelial-mesenchymal transition. Onco Targets Ther 10: 3435-3451, 2017.

8. Thiery JP, Acloque H, Huang RY and Nieto MA: Epithelial-mesenchymal transitions in development and disease. Cell 139: 871-890, 2009.

9. Qiao Y, Jiang X, Lee ST, Karuturi RK, Hooi SC and Yu Q: FOXQ1 regulates epithelial-mesenchymal transition in human cancers. Cancer Res 71: 3076-3086, 2011.

10. ZeisbergMandNeilsonEG:Biomarkersforepithelial-mesenchymal transitions. J Clin Invest 119: 1429-1437, 2009.

11. De Craene B and Berx G: Regulatory networks defining EMT during cancer initiation and progression. Nat Rev Cancer 13: 97-110, 2013.

12. Zhang J, Zhou Y and Yang Y: CCR7 pathway induces epithelial-mesenchymal transition through up-regulation of Snail signaling in gastric cancer. Med Oncol 32: 467, 2015.

13. Liu AN, Zhu ZH, Chang SJ and Hang XS: Twist expression associated with the epithelial-mesenchymal transition in gastric cancer. Mol Cell Biochem 367: 195-203, 2012. 
14. Huang L, Wu RL and Xu AM: Epithelial-mesenchymal transition in gastric cancer. Am J Transl Res 7: 2141-2158, 2015.

15. Jia LT, Wu J, Zhang L, Chen J, Zhong D, Xu S, Xie C and Cai J: Restoration of miR-1228* expression suppresses epithelial-mesenchymal transition in gastric cancer. PLoS One 8: e58637, 2013.

16. Liu S, Cui J, Liao G, Zhang Y, Ye K, Lu T, Qi J and Wan G: miR-137 regulates epithelial-mesenchymal transition in gastrointestinal stromal tumor. Tumor Biol 35: 9131-9138, 2014.

17. Sakimura S, Kurashige J, Sugimachi K, Ueda M, Hirata H, Shinden Y, Sakimura E, Matsumura T, Takano Y, Uchi R, et al: Decreased expression of miR-506 induced epithelial-mesenchymal transition and poor prognosis in gastric cancer patients. Cancer Res 74: 2014.

18. Rivera MN, Kim WJ, Wells J, Driscoll DR, Brannigan BW, Han M, Kim JC, Feinberg AP, Gerald WL, Vargas SO, et al: An $\mathrm{X}$ chromosome gene, WTX, is commonly inactivated in Wilms tumor. Science 315: 642-645, 2007.

19. Akhavanfard S, Vargas SO, Han M, Nitta M, Chang CB, Le LP, Fazlollahi L, Nguyen Q, Ma Y, Cosper A, et al: Inactivation of the tumor suppressor WTX in a subset of pediatric tumors. Genes Chromosomes Cancer 53: 67-77, 2014.

20. Kim WJ, Wittner BS, Amzallag A, Brannigan BW, Ting DT, Ramaswamy S, Maheswaran S and Haber DA: The WTX tumor suppressor interacts with the transcriptional corepressor TRIM28. J Biol Chem 290: 14381-14390, 2015.

21. QingLing Z, LiNa Y, Li L, Shuang W, YuFang Y, Yi D, Divakaran J, Xin L and YanQing D: LMP1 antagonizes $\mathrm{WNT} / \beta$-catenin signalling through inhibition of WTX and promotes nasopharyngeal dysplasia but not tumourigenesis in LMP1(B95-8) transgenic mice. J Pathol 223: 574-583, 2011.

22. Fujita A, Ochi N, Fujimaki H, Muramatsu H, Takahashi Y, Natsume J, Kojima S, Nakashima M, Tsurusaki Y, Saitsu H, et al: A novel WTX mutation in a female patient with osteopathia striata with cranial sclerosis and hepatoblastoma. Am J Med Genet A 164A: 998-1002, 2014.

23. Zhang YY, Wang QM, Niu HL, Liu X and Zhang QL: The general expression analysis of WTX gene in normal and cancer tissues. Pathol Oncol Res 23: 439-446, 2017.

24. Ma W, He L, Liu C, Zhang Q and Ding Y: Establishment of a colorectal cancer SW620 cell line stably over-expressing Wilm's tumor on $\mathrm{X}$ chromosome using a recombinant lentivirus vector. Nan Fang Yi Ke Da Xue Xue Bao 35: 1122-1127, 2015 (In Chinese).

25. Livak KJ and Schmittgen TD: Analysis of relative gene expression data using real-time quantitative PCR and the 2(-Delta Delta C(T)) method. Methods 25: 402-408, 2001.

26. Xu J, Lamouille S and Derynck R: TGF-beta-induced epithelial to mesenchymal transition. Cell Res 19: 156-172, 2009.
27. Wendt MK, Allington TM and Schiemann WP: Mechanisms of the epithelial-mesenchymal transition by TGF-beta. Future Oncol 5: 1145-1168, 2009.

28. Wu C, Zhuang Y, Jiang S, Liu S, Zhou J, Wu J, Teng Y, Xia B, Wang $R$ and Zou $X$ : Interaction between $W n t / \beta$-catenin pathway and microRNAs regulates epithelial-mesenchymal transition in gastric cancer (Review). Int J Oncol 48: 2236-2246, 2016.

29. Camargo MC, Kim WH, Chiaravalli AM, Kim KM, Corvalan AH, Matsuo K, Yu J, Sung JJ, Herrera-Goepfert R, Meneses-Gonzalez F, et al: Improved survival of gastric cancer with tumour Epstein-Barr virus positivity: An international pooled analysis. Gut 63: 236-243, 2014.

30. Deng JY and Liang H: Clinical significance of lymph node metastasis in gastric cancer. World J Gastroenterol 20: 3967-3975, 2014.

31. Martinez Mier G, Alvarez-Tostado Fernandez JF, Romero Hernandez T, Martinez MierEA and Blanco Benavides R: Morbidity and mortality in surgery for gastric cancer. Rev Gastroenterol Mex 64: 78-84, 1999 (In Spanish).

32. Comai G, Boutet A, Neirijnck Y and Schedl A: Expression patterns of the Wtx/Amer gene family during mouse embryonic development. Dev Dyn 239: 1867-1878, 2010.

33. Xia P and Xu XY: Epithelial-mesenchymal transition and gastric cancer stem cell. Tumour Biol 39, 2017.

34. Huang J, Xiao D, Li G, Ma J, Chen P, Yuan W, Hou F, Ge J, Zhong M, Tang Y, et al: EphA2 promotes epithelial-mesenchymal transition through the $\mathrm{Wnt} / \beta$-catenin pathway in gastric cancer cells. Oncogene 33: 2737-2747, 2014.

35. Li K and Dan Z: Research progress of Wnt $/ \beta$-catenin signaling pathway in prevention and treatment of gastric cancer. Nan Fang Yi Ke Da Xue Xue Bao 34: 1852-1856, 2014 (In Chinese).

36. Heuberger J and Birchmeier W: Interplay of cadherin-mediated cell adhesion and canonical Wnt signaling. Cold Spring Harb Perspect Biol 2: a002915, 2010

37. Howard S, Deroo T, Fujita $\mathrm{Y}$ and Itasaki N: A positive role of cadherin in Wnt/ $\beta$-catenin signalling during epithelial-mesenchymal transition. PLoS One 6: e23899, 2011.

38. Hlubek F, Jung A, Kotzor N, Kirchner T and Brabletz T: Expression of the invasion factor laminin gamma2 in colorectal carcinomas is regulated by beta-catenin. Cancer Res 61: 8089-8093, 2001.

39. Major MB, Camp ND, Berndt JD, Yi X, Goldenberg SJ, Hubbert C, Biechele TL, Gingras AC, Zheng N, Maccoss MJ, et al: Wilms tumor suppressor WTX negatively regulates WNT/beta-catenin signaling. Science 316: 1043-1046, 2007.

(7) $\Theta$ This work is licensed under a Creative Commons Attribution-NonCommercial-NoDerivatives 4.0 International (CC BY-NC-ND 4.0) License. 